\title{
Effects of Cold Atmospheric Plasma Jet Treatment on the Seed Germination and Enhancement Growth of Watermelon
}

\author{
Khaled Lotfy ${ }^{1,2}$ \\ ${ }^{1}$ King Marriott Higher Institute of Engineering \& Technology, Alexandria, Egypt \\ ${ }^{2}$ University College of Taiyma, Tabuk University, Tabuk, KSA \\ Email: Khaledlotfy52@yahoo.com
}

How to cite this paper: Lotfy, K. (2017) Effects of Cold Atmospheric Plasma Jet Treatment on the Seed Germination and Enhancement Growth of Watermelon. Open Journal of Applied Sciences, 7, 705719.

https://doi.org/10.4236/ojapps.2017.712050

Received: November 24, 2017

Accepted: December 25, 2017

Published: December 28, 2017

Copyright $\odot 2017$ by author and Scientific Research Publishing Inc. This work is licensed under the Creative Commons Attribution International License (CC BY 4.0).

http://creativecommons.org/licenses/by/4.0/

\begin{abstract}
The current study was carried out to reveal the possible impacts of nonthermal plasma on water uptake by seeds, seed germination and vigor of seedlings of watermelon seeds using cold plasma jet at atmospheric pressure and room temperature. Cold atmospheric plasma jet with nitrogen gas sources was employed in this study. Five treatment doses and one control were used to conduct germination parameters. The effects of the different duration time of cold atmospheric plasma on the germination of treated watermelon seeds were studied. The cold plasma operated at $3 \mathrm{Kv}$ and $14 \mathrm{l} / \mathrm{min}$ as a fixed input voltage and a fixed flow rate respectively. Cold atmospheric plasma increased the germination percentage of watermelon as well as the growth parameters (root and shoot length, dry weight), and the vigor of seedlings. The effects of cold plasma during this study depended on exposure time. The operation time of $4 \mathrm{~min}$ considered as an appropriate plasma dose to promote the germination parameters.
\end{abstract}

\section{Keywords}

Non-Thermal Plasma, Atmospheric Plasma, Germination Rate, Vigor Index

\section{Introduction}

Physical methods like radiation, high electromagnetic field, microwave irradiation and cold atmospheric pressure plasma play a vital role solely in medication for microorganism decontamination [1], however also are helpful for industrial purposes, e.g. for increasing surface hydrophilicity and material surface modification [2]. However, a promising physical technique that gives a broad vary of 
interesting industrial applications is cold atmospheric plasma which generated at low temperature [3]. Cold atmospheric plasma devices are a basic tool in a wide range of technological and bio-medical applications. [4] [5] [6]. On the other hand, in last two decades, several cold atmospheric plasma devices were investigated, as have their use with thermally sensitive materials and medical applications [7]-[13]. The plasma treatment creates a complex mixture of surface functionalities that influence surface physical and chemical properties and leads to a dramatic modification of wetting behavior of the surface [14] [15] [16]. Not solely the chemical structure but additionally the roughness of the surface is affected by the plasma treatment; this also might change the wettability of the surface [17]. It has also been demonstrated that wetting of biological tissue might be changed by low-temperature radio frequency plasma [18] [19] [20]. Cold (nonequilibrium) radiofrequency plasma treatment of biological objects becomes a very important tool for modification of their chemical and physical properties [18] [19] [20] [21].

One of the potential areas of cold plasma research is plant cultivation, particularly pre-sowing treatment by cold atmospheric plasma technique [22]. Promising results have been reported with regard to increasing seed germination rate, activity and reduction in germination time [23] [24] [25], increasing wettability and, implicitly, water absorption [26], and for decontamination of grains and vegetables seeds [27] [28], enzyme activity [29] [30], and also the yield of plants [31]. There are still several open problems with respect to the mechanisms of plasma action on cells and tissues [21]. As an example, physical and chemical mechanisms of the interaction of cold plasmas with tissues and therefore the actual roles of various plasma constituents in tissue treatment remain enigmatic. On the other hand, cold atmospheric plasma was considered as an economical and safe approach for seeds treatment with regard to the normal chemical methods. It's known that, the traditional chemical methods were usually uneconomic as results of large amounts of chemicals were required, and some residual chemicals on the seeds coat would bring soil pollution. For the cold plasma treatment, its damage to the seeds was quite weak as a result of the active substances might solely enter the seeds approximately several nanometers [32] [33], and therefore the residual environmental pollutants were quite few.

Melon is a very important horticultural crop cultivated mostly in arid and semi-arid region of the world where salinity, high temperature, fast soil drying, and crust formation are barriers to good melon crop establishment. In several seeds, germination can be inhibited by mechanical restriction exerted by the seed coat. Permeability limitation of water and gases is typical attributable to hard seed coat. However, the large seed cavity in the watermelon and imbibed coat serves as a continuous wet layer around the embryo by which the oxygen must transverse.

Moreover, no study has been previously reported on the effects of cold atmospheric plasma on melon seeds germination and early seedling growth. In 
this paper, the cold atmospheric plasma jets (CAPJ) application for seeds surface modification and changes in the dynamics of water uptake into the watermelon seeds is reported. The authors also investigate the optimization of the operating conditions in cold atmospheric plasma to increase the percentage germination and total vigor of seedlings. Also, the current study aims to prove that the seeds germination and early growth of watermelon change after seeds pretreatment by cold atmospheric plasma jet, and seeks a beneficial treatment dosage for the seeds.

\section{Materials and Methods}

\subsection{Plant Material}

The popular Niagara watermelon seeds were obtained locally from Saudi Arabia market. Two hundred randomly selected fresh seeds and stored at $25^{\circ} \mathrm{C}$ in the dark until reached dried stage.

\subsection{Characteristics of Plasma Source}

The plasma treatment of melon seeds was performed by cold atmospheric plasma jet. The cold atmospheric plasma jet system is mainly composed of electrodes, dielectrics, voltage controller, nitrogen gas and a high-voltage power supply. The high-voltage power supply is a commercially available transformer for neon light. This power supply is utilized in the cold atmospheric plasma to generate the plasma jet in order to cut the overall cost of the device by replacing the expensive RF power supply representing the major cost. The power supply has an output of $10 \mathrm{kV}, 30 \mathrm{~mA}$ and $20 \mathrm{kHz}$ which gives an output in the range of very low frequency of RF. This power supply has an overload, open circuit, earth leakage and short circuit protection. The input of this power supply is connected to $220 \mathrm{~V}, 12 \mathrm{~A}$ voltage controller. The voltage controller regulates the primary voltage of the high-voltage transformer. The electrode system of the plasma jetconsists of two parallel stainless steel disks separated by an insulator. The outer electrode (Cathode) and the inner electrode (anode) have the same thickness and diameter $15 \mathrm{~mm}$ and $2 \mathrm{~mm}$ respectively. The two electrodes are separated by an insulator material, which made of Teflon. The Teflon disk has a $1 \mathrm{~mm}$ thickness and $15 \mathrm{~mm}$ in diameter. The two electrodes and Teflon disk have center hole of $1 \mathrm{~mm}$ and $1.2 \mathrm{~mm}$ diameter respectively, through center hole nitrogen gas is flowing. The output terminals of the power supply are connected to the cathode and anode terminals of the plasma jet via a $1 \mathrm{~mm}$ single copper isolated cable as can be seen in Figure 1. The gas flow system is responsible for delivering the gas to the plasma jet at the appropriate flow-rate. It consists of the gas storage cylinder, dual-stage gas flow regulator, and gas connection rubber hose. In this study Nitrogen gas was used to test the plasma jet operation. The nitrogen gas is stored in a high-pressure gas cylinder [13].

Once nitrogen is introduced through the inner electrode and high-voltage ac power is applied, the plasma generation between the two electrodes. Sufficient 


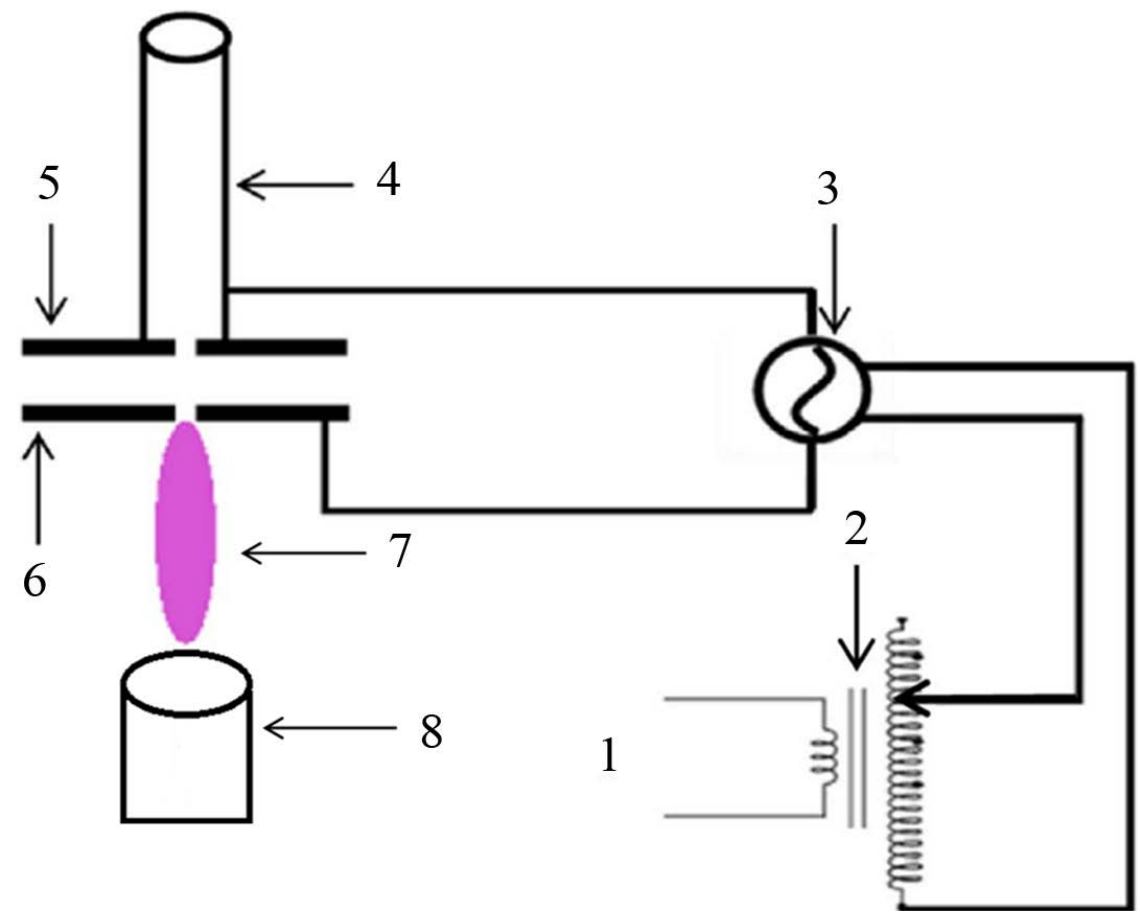

Figure 1. The electric circuit of cold atmospheric plasma jet device, 1 input electric source $220 \mathrm{~V}, 2$ voltage controllers, 3 neon power supply, 4 gas feeding through copper tube, 5 anode, 6 cathode, 7 plasma jet and 8 acrylic box.

voltage applied to nitrogen gas ionizes nitrogen atoms by driving off electrons. Free electrons can trigger further ionization of neighboring nitrogen species by a collision. This series of reactions convert the nitrogen gas to the plasma state, which is distinctly different from solid, liquid, and gas states. The device generates a room temperature plasma jet that passes through the hole of the inner electrode and extends up to $7 \mathrm{~mm}$ beyond the end of the Teflon evolve.

\subsection{Seeds Treatment}

The plasma jet ejected to the acrylic box which contain a melon seeds. From experimental results, it shows that $14 \mathrm{l} / \mathrm{min}$ of nitrogen gas and at $3 \mathrm{Kv}$ as a fixed input voltage was most suitable for plasma generation for our system. Plasma irradiation time was optimized to obtain the suitable experimental condition for the germination enhancement of melon seeds. The seeds were distributed uniformly and exposed to plasma for durations of 2, 4, 6, 8 and 10 minutes, each run contain twenty seeds. All treatments were conducted at least three replicates. The data in this study were recorded as the mean value \pm standard deviation. A GM1150 Infra-Red thermometer is employed to measure the temperature of a melon seeds to be treated. This thermometer has a measuring temperature range from -50 to $1150^{\circ} \mathrm{C}$. For the wettability measurements, the dry seeds of treated and non-treated were first weighed and recorded as $m_{1}$; afterward, they were soaked in water for $12 \mathrm{~h}$ and also the seeds weighted each $2 \mathrm{~h}$ and recorded as $m_{2}$ after absorbing the surface water on the seeds. The water uptake by seeds is 
called imbibition, which leads to the swelling and the breaking of the seed coat. The water uptake was calculated using the following equation:

$$
\text { Water uptake } \%=\frac{m_{2}-m_{1}}{m_{1}} \times 100
$$

Seeds were transferred to transparent plastic cup containing one layer of filterpaper, each cup contained twenty seeds. Seeds germination was carried out at $25^{\circ} \mathrm{C}$ in the dark. The seeds were monitored for duration of 10 days. In the $10 \mathrm{Th}$ day the germination percentage, the length and mass of roots, shoots and sprouts were measured. Subsequently, roots, shoots and sprouts were dried until a constant mass was reached, for weight determination. Plant material for dry weight was dried at $90^{\circ} \mathrm{C}$ for $96 \mathrm{~h}$. Germination characteristics were calculated using the following equations [34]:

$$
\begin{gathered}
\text { Germination rate }=\frac{\text { Number of seeds germiated in } 4 \text { days }}{\text { Total number of seeds }} \times 100 \% \\
\text { Final germination percentage }=\frac{\text { Number of germinated seeds }}{\text { Total number of seeds planted }}
\end{gathered}
$$

The seed vigor I and II were calculated in modification according to [35], using the following equation:

Seed vigor $\mathrm{I}=$ Shoot length $(\mathrm{cm})+$ Root length $(\mathrm{cm}) \times$ germination $(\%) / 100$

Seed vigor II = Dry weight of seedling $($ root + shoot $) \times$ germination $(\%) / 100$

\section{Result and Discussion}

\subsection{Seeds Temperature Measurement}

Figure 2 shows the temperature of melon seeds after plasma treatment. InfraRed thermometer is used to measure the temperature of seeds. From this figure, it can be seen that, the temperature increase continuously by increase the expose time of nitrogen plasma. At $2 \mathrm{~min}$ of operation time the seeds temperature equal room temperature $\left(25^{\circ} \mathrm{C}\right)$. Even the operation time reach $10 \mathrm{~min}$, the seeds temperature is as low as $28^{\circ} \mathrm{C}$. It mean that, cold atmospheric plasma jet present a suitable method to enhancement germination without harmful effects.

\subsection{Influence of CAPJ on Water Uptake}

The findings suggest acceleration in the water uptake of watermelon seeds treated by cold atmospheric plasma jet. From Figure 3, it can be shows that, higher and more intensive water uptake positively correlates with exposure time of cold atmospheric plasma. In the case of $4 \mathrm{~min}$ cold atmospheric plasma application dose, the most striking difference was visible after the first $2 \mathrm{~h}$, when the seeds absorbed 52\% more water compared to the control (37\%). In contrast, longer imbibition time causes a decrease in the dynamics of water uptake in plasma treated seeds. These findings suggest that plasma treated seeds reached water-saturation significantly faster compared to untreated seeds. After $12 \mathrm{~h}$ the 


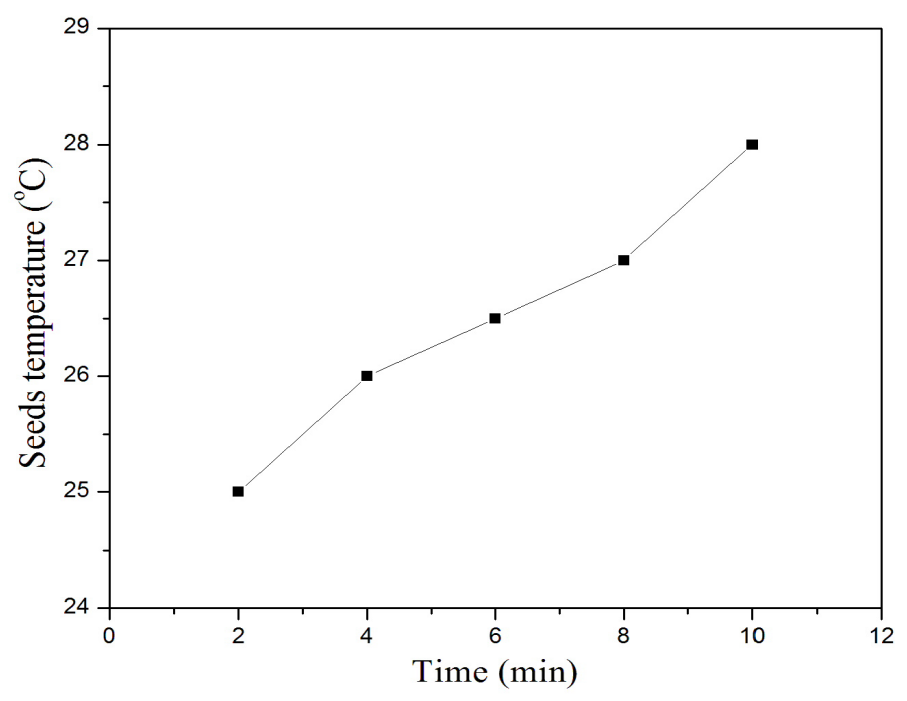

Figure 2. The temperature of melon seeds after plasma treatment.

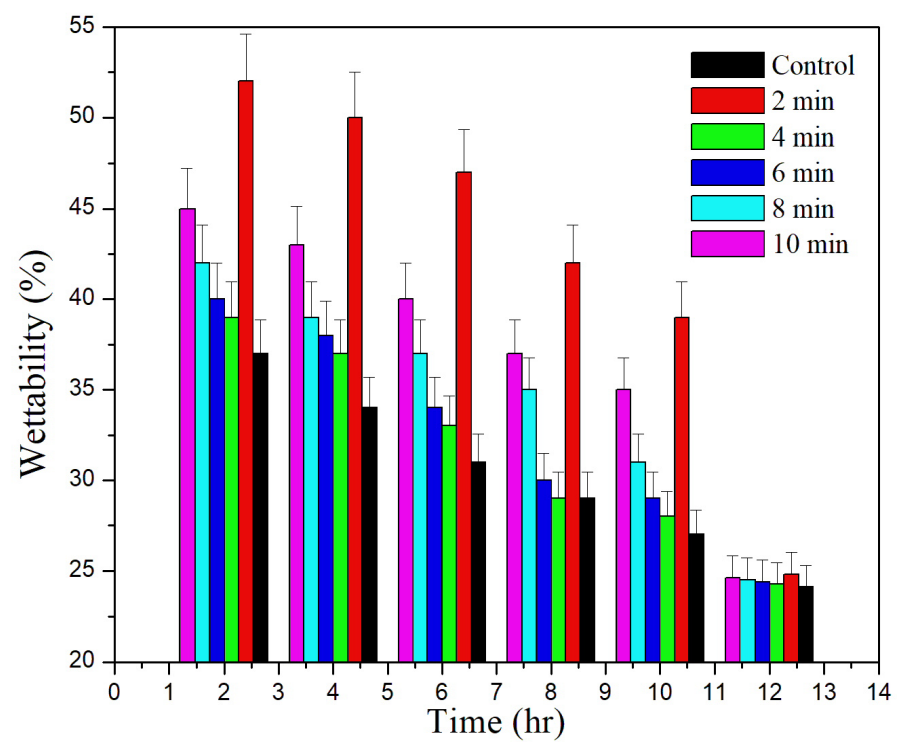

Figure 3. The wettability of treated and untreated melon seeds through $12 \mathrm{~h}$ soaked in water.

seeds were mostly well-watered in all variants, and there were no significant differences among the variants [36].

\subsection{Germination Rate}

The results of melon seed germination rates after the cold atmospheric plasma treatments were shown in Figure 4. On the 4th day of plant, the germination rate was $5 \%$ for untreated seeds. On the other hand, it can be seen that the plasma treatment has a dramatic effect on melon seeds. The germination rate was $10 \%, 60 \%, 40 \% 30 \%$ and $35 \%$ at $2,4,6,8$ and 10 min operation time of CAPJ treatment. After 4 days of cultivation, it can be seen that, the cotyledon could be observed only for 4, 6, 8 and $10 \mathrm{~min}$ expose plasma irradiation (Figure 5). As 


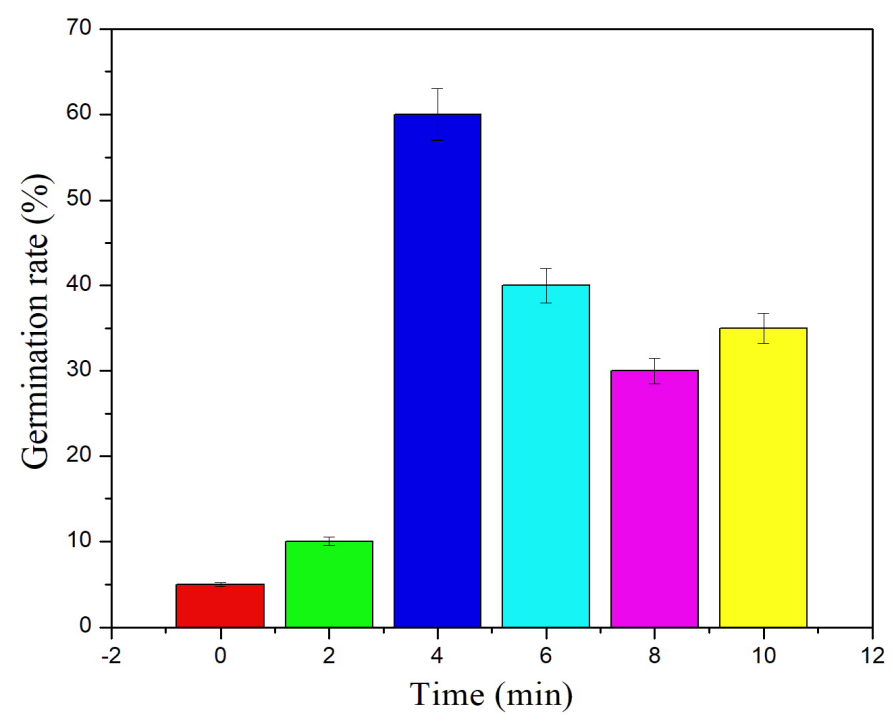

Figure 4. Germination rates of treated and untreated melon seeds.

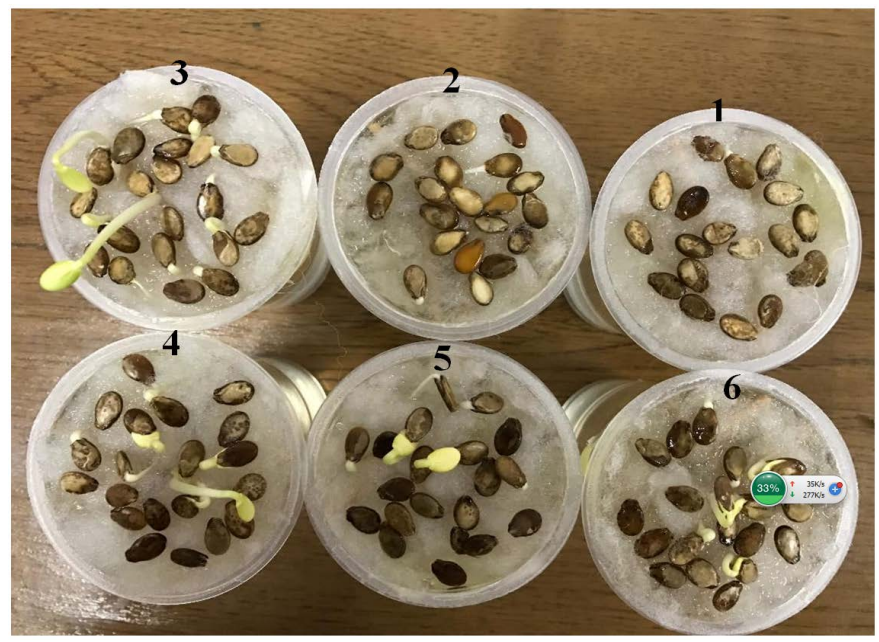

Figure 5. The treated and untreated melon seeds after 4 days of cultivation; (1) untreated; (2) 2 min irradiated; (3) 4 min irradiated; (4) 6 min irradiated; (5) 8 min irradiated and (6) 10 min irradiated.

compared to untreated seeds, the cold atmospheric plasma jet has enhanced the seeds germination rate and the seedling growth. It is demonstrated that the reactive oxygen and nitrogen species (RONS) are the main signaling molecules regulating many developmental processes in mammalian, fungi, and plants. The required quantity of reactive species in plants can play an important role on the regulation of growth and development [37]. However, RNS and ROS species have positive effect on abscisicacid production, which is the pivotal hormone responsible for ignition and maintenance of the seed dormancy [38]. However, Figure 6 shows the effect of cold atmospheric plasma on germination percentage after 10 days. From this figure, it can observed that, the germination percentage of watermelon seeds were also different after cold atmospheric plasma treatment. The germination percentage increased by $72 \%, 93.5 \%, 75 \%, 87 \%$ and $85 \%$ 


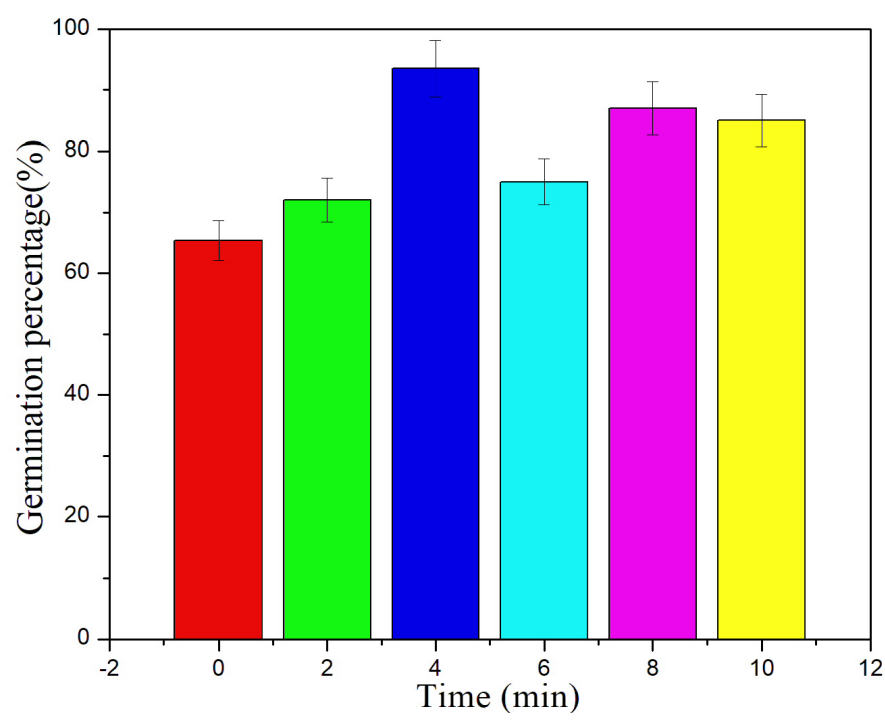

Figure 6. Germination percentage of treated and untreated melon seeds after 10 days of cultivation.

at 2, 4, 6, 8 and 10 min operation time of cold plasma treatment respectively. But, the germination percentage increased by $65.5 \%$ for untreated watermelon seeds. These results indicated that the cold atmospheric plasma has a significant effect in enhancement the germination percentage for watermelon seeds. Moreover, the active particles generated by the cold plasma could penetrate through the seeds coat and directly influenced cells inside the seeds; while the seeds coat operated like a partially permeable membrane, which only allowed passage of certain small ions or particles [24].

\subsection{Seedling Growth: Shoot and Root Length}

The positive effect of cold atmospheric plasma is observed between untreated and treated melon seeds on the short term germination and seedling growth. Therefore, in order to understand the long term combined effect of plasma treated melon seeds, the shoot and root lengths of melon seeds were measured after 10 days of agriculture. Figure 7 shows the effects of plasma treatment seedling growth of melon seeds. It can be observed the shoot + root length of seeds which treated by plasma longer than control on after 10 days. The root length was $6 \mathrm{~cm}$ for untreated melon, but increased to $12.5,14,10,9.1$ and $8.4 \mathrm{~cm}$ for 2, 4, 6, 8 and 10 min expose plasma irradiation respectively. Similarly, the shoot length was $13 \mathrm{~cm}$ for untreated melon, while it was significantly enhanced to $21,24.5,18.5,16$, and $14.5 \mathrm{~cm}$ for 2, 4, 6, 8 and 10 min expose plasma irradiation respectively. It can notice that, the operation time of 4 min considered as an appropriate plasma dose to promote the root and shoot growth. Many researches have demonstrated that, the cold plasma treatment could promote seedling growth of plants; Dhayal et al. [39] reported that the seedling growth of Carthamustinctorius L. was significantly enhanced by a cold plasma treatment; Zhou et al. [40] observed that the tomato seedling growth was improved by an 


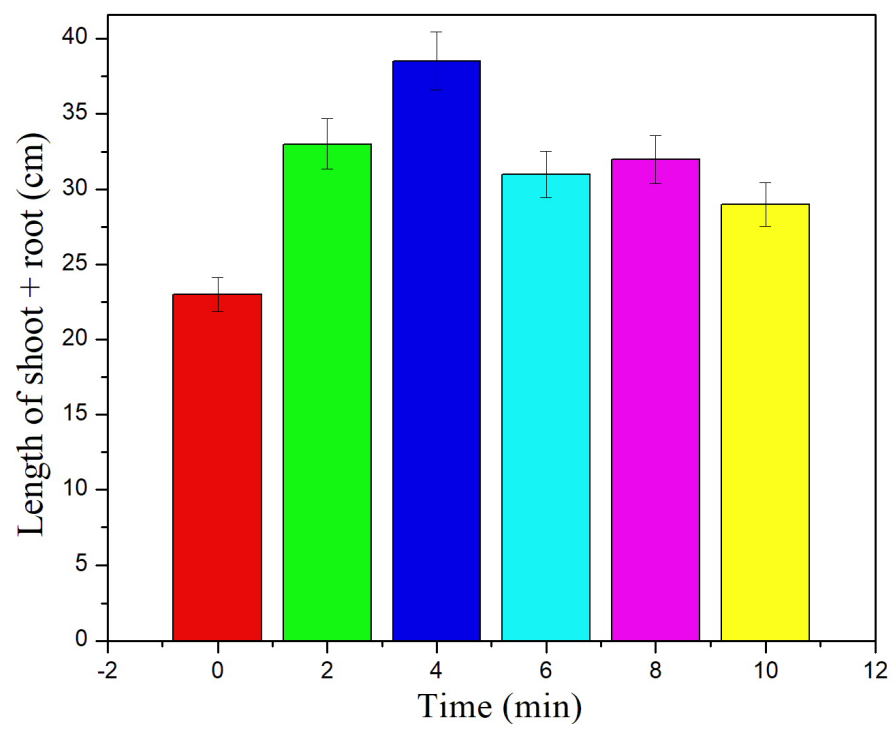

Figure 7. Seedling growth (shoot and root length) of treated and untreated melon seeds.

atmospheric pressure plasma treatment; Sera et al. [24] also found that wheat and oat seedling growth was enhanced by a cold plasma treatment. Moreover, $\mathrm{Li}$ et al. reported that a cold plasma treatment with an appropriate energy level promoted the soybean seedling growth, while much lower or higher energy levels did not show any promoting effects [33].

\subsection{Dry Weight of Seedling}

Under influence of CAPJ in the time range of $0-10 \mathrm{~min}$ the seedling dry weight (Figure 8) significantly increased. The weight of dry matter accumulations in the plants grown from the nitrogen plasma treated seeds were approximately $68.35 \mathrm{mg}$ under treatment duration of $4 \mathrm{~min}$ and 10 days after sowing, while it was slightly lower in case control seeds $(55.52 \mathrm{mg}$ ). Overall, nitrogen plasma treatment were produced the most favourable condition of plant growth activity and dry matter accumulation with respect to control seeds. The seedling emergence test showed that nitrogen plasma pretreatment changed the sprouting speed of watermelon seeds, resulting in alteration of the strong seedling percentage. The first sprout occurred from the fourth day after sowing for plasma treatment seeds while occurred after six days for control one (Figure 5). These results indicate that, the emergence acceleration of sprout by plasma treatment enhancement the weight of seedling.

It known that, in the $\mathrm{N}_{2}$ atmosphere, $\mathrm{N}_{2}$ molecules could be excited and ionized by high-energy electrons when the discharge plasma occurred, generating. $\mathrm{N}$ radicals and $\mathrm{N}_{2}^{+}$, as shown in the following reactions [41].

$$
\begin{aligned}
& \mathrm{e}+\mathrm{N}_{2} \rightarrow 2 \mathrm{e}+\mathrm{N}_{2}^{+} \\
& \mathrm{e}+\mathrm{N}_{2} \rightarrow \mathrm{e}+2 \mathrm{~N}
\end{aligned}
$$

Previous research showed that plasma-induced actions on the seed coat could 


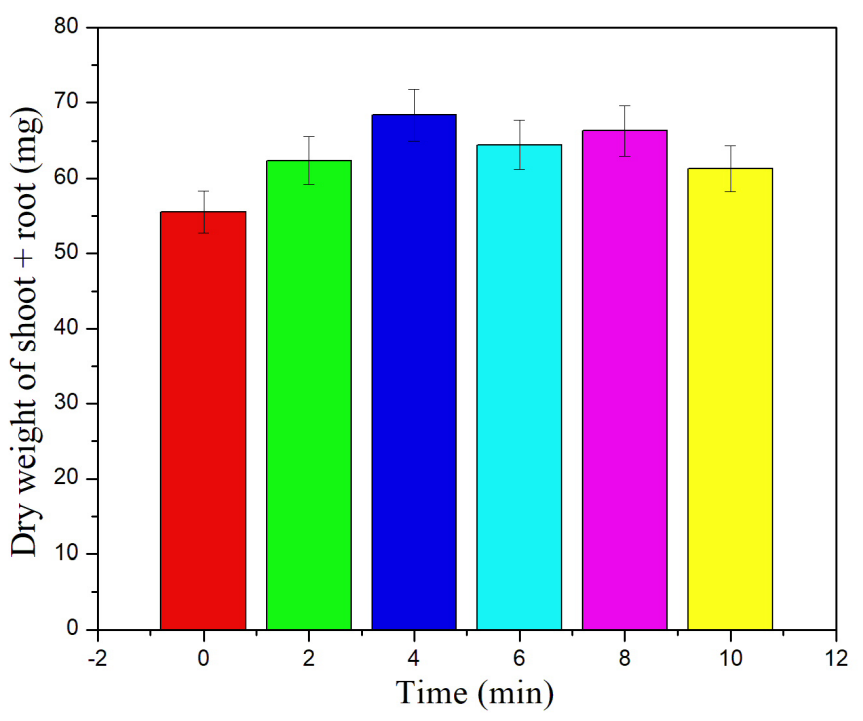

Figure 8. Dry weight of seedling of treated and untreated melon seeds.

lead to the penetration of active species (such as reactive ions) and UV into seeds, which probably affect the physiological reactions, seed germination and growth [42] [43].

\subsection{Vigor Index}

All treated seeds have higher value of vigor index I and II as can be seen in Figure 9. The highest positive responses were found when the seeds were treated for $4 \mathrm{~min}$. An intensity of $4 \mathrm{~min}$ cold atmospheric plasma produced increases in vigor index I and II, $17 \%$ and 25\%respectively compared to the control seeds. However, there has been approximately a $5 \%-40 \%$ decrease in yield for seeds with low vigor compared with seeds with high vigor [44]. From our results, cold atmospheric plasma jet leads to significance enhancement seed vigor so that high-quality yield in agricultural production will be produced. Finally, due to the higher root and shoot length for treated seeds with respect control one; the vigor indexes of treated seeds were significantly higher than that of the control. So that, appropriate nitrogen cold atmospheric plasma treatment can enhance seed vigor index in laboratory conditions.

\subsection{Dry Sprouts Weight}

The growth enhancement of watermelon measured by brought sprouts to dehydrate after measuring the length of root. The melon sprouts were dehydrated at $90^{\circ} \mathrm{C}$ for $96 \mathrm{~h}$ and was weighted by digital balance. The total mass was calculated in the percentages from the ratio of the weight of sprout between pre and post dehydration process. From result, as can be seen in Figure 10, it could be observed that, all treated seeds had a greater mass compared control one. This could be proved that cold atmospheric plasma has a positive effect on germination enhancement. Previous research showed that the dry mas of radish sprouts 


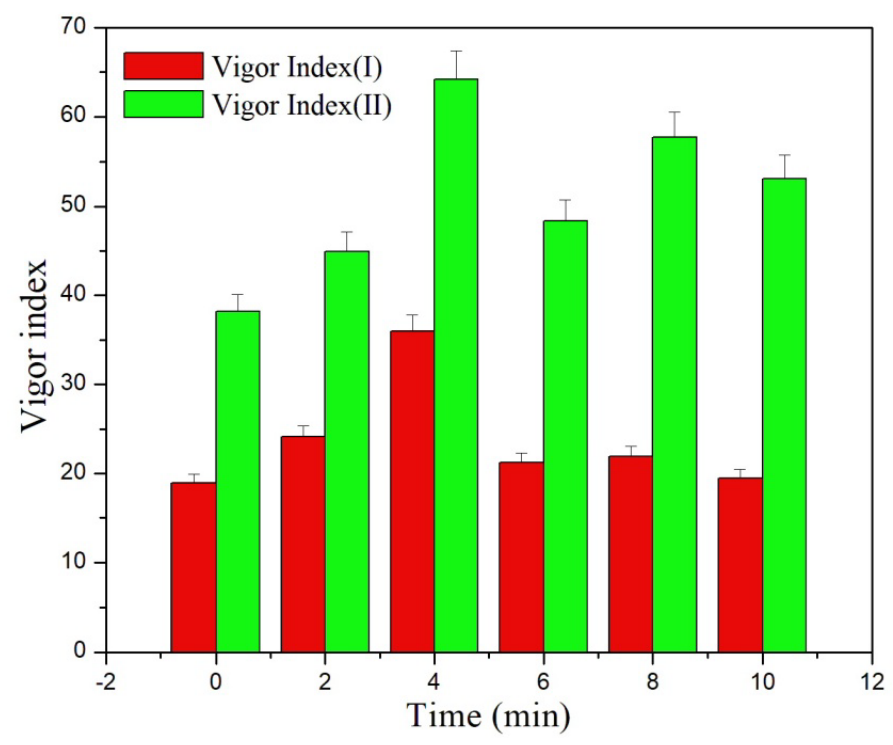

Figure 9. Vigor index of treated and untreated melon seeds.

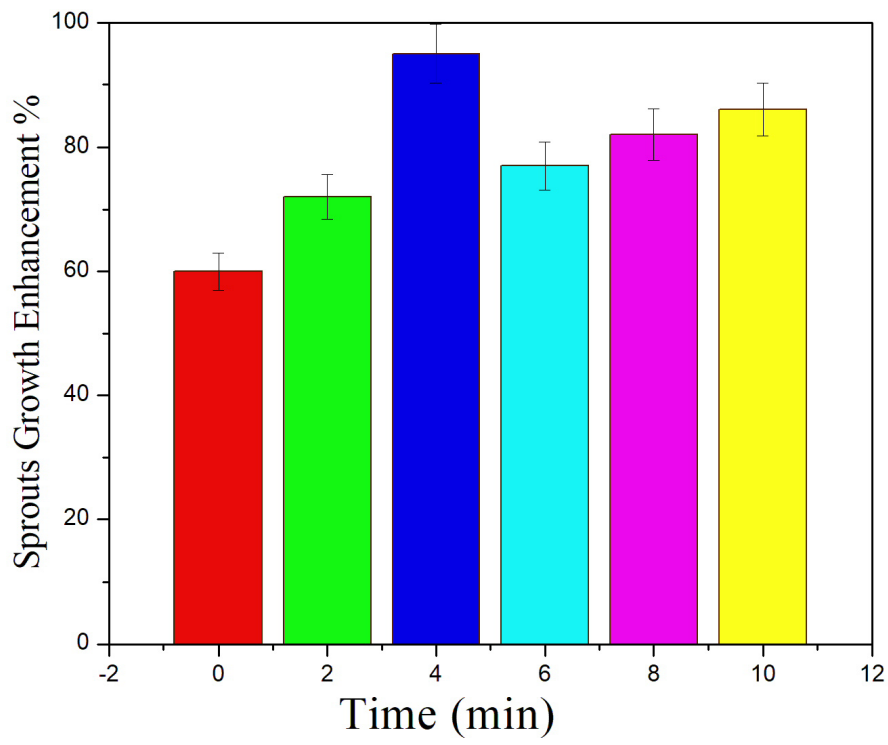

Figure 10. Dry sprouts weight of treated and untreated melon seeds.

which treated by non-thermal plasma recorded higher value with respect to untreated one [45].

\section{Conclusion}

The important advantage of the cold atmospheric plasma jet treatment of seeds is that the plasma source is capable working in wet and dusty environments and continuous mode. Nitrogen cold atmospheric plasma jet induced germination and growth of melon seeds was investigated in this study. The water uptake by seeds, seed germination and vigor of seedlings all improved after plasma treatment with an appropriate plasma dose, as well as the seedlings length and 
weight. Cold atmospheric plasma treatments exhibited significant differences compared with the control seeds. Cold atmospheric plasma provided a dramatic solution of slow germination rate due to hard seed coat of watermelon, which prevents penetration of water and gases. The fast emergence of treated seeds with respect to untreated one can be attributed to the dramatic increase of wettability which leads to the enhancement of Seedling.

\section{References}

[1] Fridman, G., Friedman, G., Gutsol, A., et al. (2008) Applied Plasma Medicine. Plasma Processes and Polymers, 5, 503-533.

https://doi.org/10.1002/ppap.200700154

[2] Ŝimor, M., Ráhê̂, J., Vojtek, P., et al. (2002) Atmospheric-Pressure Diffuse Coplanar Surface Discharge for Surface Treatments. Applied Physics Letters, 81, 2716-2718. https://doi.org/10.1063/1.1513185

[3] Černák, M., Černáková, L'., Hudec, I., et al. (2009) Diffuse Coplanar Surface Barrier Discharge and Its Applications for In-Line Processing of Low-Added-Value Materials. The European Physical Journal Applied Physics, 47, p1-p6.

[4] Graves, D.B. (2014) Low Temperature Plasma Biomedicine: A Tutorial Review. Physics of Plasmas, 21, 080901. https://doi.org/10.1063/1.4892534

[5] Kong, M.G., Morfill, G. and Stolz, W. (2012) Plasma Medicine Applications of Low-Temperature Gas Plasmas in Medicine and Biology Plasma Medicine. In: Laroussi, M., Cambridge University Press, Cambridge.

[6] Lu, X., Naidis, G.V., Laroussi, M., Reuter, S., Graves, D.B. and Ostrikov, K. (2016) Reactive Species in Non-Equilibrium Atmospheric-Pressure Plasmas: Generation, Transport, and Biological Effects. Physics Reports, 630, 1-84.

https://doi.org/10.1016/j.physrep.2016.03.003

[7] Kolb, J.F., Mohamed, A.-A.H., Price, R.O., et al. (2008) Cold Atmospheric Pressure air Plasma Jet for Medical Applications. Applied Physics Letters, 92, 241501241503.

[8] Lu, X.-P., Jiang, Z.-H., Xiong, Q., et al. (2008) An $11 \mathrm{~cm}$ Long Atmospheric Pressure Cold Plasma Plume for Applications of Plasma Medicine. Applied Physics Letters, 92, 081502-081504. https://doi.org/10.1063/1.2883945

[9] Hong, Y.C., Cho, S.C., Kim, J.H. and Uhm, H.S. (2007) A Long Plasma Column in Aflexible Tube at Atmospheric Pressure. Physics of Plasmas, 14, 074502-074505.

[10] Zhang, X., Li, M., Zhou, R., Feng, K. and Yang, S. (2008) Ablation of Liver Cancer Cells in Vitro by a Plasma Needle. Applied Physics Letters, 93, 021502-021504.

[11] Hong, Y.C., Uhm, H.S. and Yi, W.J. (2008) Atmospheric Pressure Nitrogen Plasma Jet: Observation of Striated Multilayer Discharge Patterns. Applied Physics Letters, 93, 051504-051506.

[12] Nie, Q.-Y., Ren, C.-S., Wang, D.-Z. and Zhang, J.-L. (2008) A Simple Cold Ar Plasma Jet Generated with Afloating Electrode at Atmospheric Pressure. Applied Physics Letters, 93, 011503-011505. https://doi.org/10.1063/1.2956411

[13] Lotfy, K. (2017) Cold Plasma Jet Construction to Use in Medical, Biology and Polymer Applications. Journal of Modern Physics, 8, 1901-1910. https://doi.org/10.4236/jmp.2017.811113

[14] France, R.M. and Short, R.D. (1998) Plasma Treatment of Polymers: The Effects of Energy Transfer from an Argon Plasma on the Surface Chemistry of Polystyrene, 
and Polypropylene. A High-Energy Resolution X-Ray Photoelectron Study. Langmuir, 14, 4827-4835. https://doi.org/10.1021/la9713053

[15] France, R.M. and Short, R.D. (1997) Effects of Energy Transfer from an Argon Plasma on the Surface Chemistry of Poly(styrene), Low Density Poly(ethylene), Poly(propylene) and Poly(ethylene terephthalate). Journal of the Chemical Society, Faraday Transactions, 93, 3173-3178. https://doi.org/10.1039/a702311a

[16] Wild, S. and Kesmodel, L.L. (2001) High Resolution Electron Energy Loss Spectroscopy Investigation of Plasma-Modified Polystyrene Surfaces. Journal of Vacuum Science \& Technology A, 19, 856-860. https://doi.org/10.1116/1.1359531

[17] Lommatzsch, U., Noeske, M., Degenhardt, J., Wübben, T., Strudthoff, S., Ellinghorst, G. and Hennemann, O.-D. (2007) Pretreatment and Surface Modification of Polymers via Atmospheric-Pressure Plasma Jet Treatment. In: Mittal, K.L., Ed., Polymer Surface Modification: Relevance to Adhesion, Vol. 4, VSP/Brill, Leiden, 25-32. https://doi.org/10.1163/ej.9789067644532.i-306.10

[18] Canal, Molina, R., Bertran, E. and Erra, P. (2008) Study on the Influence of Scouring on the Wettability of Keratin Fibers before Plasma Treatment. Fibers Polymers, 9, 444-449. https://doi.org/10.1007/s12221-008-0071-8

[19] Molina, Jovancic, P., Jocic, D., Bertran, E. and Erra, P. (2003) Surface Characterization of Keratin Fibres Treated by Water Vapour Plasma. Surface and Interface Analysis, 35, 128-135. https://doi.org/10.1002/sia.1510

[20] Bormashenko and Grynyov, R. (2012) Plasma Treatment Induced Wetting Transitions on Biological Tissue (Pigeon Feathers). Colloids Surfaces B, 92, 367-371. https://doi.org/10.1016/j.colsurfb.2011.11.053

[21] Stoffels, E., Sakiyama, Y. and Graves, D.B. (2008) Cold Atmospheric Plasma: Charged Species and Their Interactions with Cells and Tissues. IEEE Transactions on Plasma Science, 36, 1441-1451. https://doi.org/10.1109/TPS.2008.2001084

[22] Ito, M. and Ohta, T. (2012) Plasma Agriculture. Journal of the Korean Physical Society, 60, 937-943. https://doi.org/10.3938/jkps.60.937

[23] Dhayal, M., Lee, S.-Y. and Park, S.-U. (2006) Application of Low-Temperature Substrate Bonding in Fabrication of Reusable Micro-Fluidic Devices. Vacuum, 80, 499-506. https://doi.org/10.1016/j.vacuum.2005.06.008

[24] Sera, B., Spatenka, P., Sery, M., Vrchotova, N. and Hruskova, I. (2010) Influence of Plasma Treatment on Wheat and Oat Germination and Early Growth. IEEE Transactions on Plasma Science, 38, 2963-2967. https://doi.org/10.1109/TPS.2010.2060728

[25] Lynikiene, S., Pozeliene, A. and Rutkauskas, G. (2006) Influence of Corona Discharge Field on Seed Viability and Dynamics of Germination. International Agrophysics, 20, 195-200.

[26] Bormashenko, E., Grynyov, R., Bormashenko, Y. and Drori, E. (2012) Cold Radiofrequency Plasma Treatment Modifies Wettability and Germination Speed of Plant Seeds. Scientific Reports, 2, 741. https://doi.org/10.1038/srep00741

[27] Selcuk, M., Oksuz, L. and Basaran, P. (2008) Decontamination of Grains and Legumes Infected with Aspergillus spp. and Penicillum spp. by Cold Plasma Treatment. Bioresurse Technology, 99, 5104-5109. https://doi.org/10.1016/j.biortech.2007.09.076

[28] Basaran, P., Basaran-Akgul, N. and Oksuz, L. (2008) Elimination of Aspergillusparasiticus from Nut Surface with Low Pressure Cold Plasma (LPCP) Treatment. Food Microbiology, 25, 626-632. https://doi.org/10.1016/j.fm.2007.12.005 
[29] Henselovâ, M., Slováková, L., Martinka, M., et al. (2012) Growth, Anatomy and Enzyme Activity Changes in Zeamays L. Roots Induced by Treatment of Seeds with Low-Temperature Plasma. Biologia, 67, 490-497. https://doi.org/10.2478/s11756-012-0046-5

[30] Surowsky, B., Fischer, A., Schlueter, O., et al. (2013) Cold Plasma Effects on Enzyme Activity in a Model Food System. Innovative Food Science and Emerging Technologies, 19, 146-152. https://doi.org/10.1016/j.ifset.2013.04.002

[31] Yin, M.Q., Huang, M.G., Ma, B.Z., et al. (2005) Stimulating Effects of Seed Treatment by Magnetized Plasma on Tomato Growth and Yield. Plasma Science and Technology, 7, 3143-3147. https://doi.org/10.1088/1009-0630/7/6/017

[32] Denes, F., Manolache, S. and Young, R.A. (1999) Synthesis and Surface Functionalization under Cold-Plasma Conditions. Journal of Photopolymer Science and Technology, 12, 27-38. https://doi.org/10.2494/photopolymer.12.27

[33] Li, L., Jiang, J.F., Li, J.G., Shen, M.C., He, X., Shao, H.L. and Dong, Y.H. (2014) Effects of Cold Plasma Treatment on Seed Germination and Seedling Growth of Soybean. Scientific Reports, 4, 5859-5865.

[34] Tong, J.Y., He, R., Zhang, X.L., Zhan, R.T., Chen, W.W. and Yang, S.Z. (2014) Effects of Atmospheric Pressure Air Plasma Pretreatment on the Seed Germination and Early Growth of Andrographis paniculata. Plasma Science and Technology, 16, 260-266. https://doi.org/10.1088/1009-0630/16/3/16

[35] Abdul-Baki, A.A. and Anderson, J.D. (1973) Vigour Determination in Soybean Seed by Multiplication. Crop Science, 3, 630-633. https://doi.org/10.2135/cropsci1973.0011183X001300060013x

[36] Stolàik, T., Henselovà, M., Martinka, M., Novák, O., Zahoranová, A. and Cernák, M. (2015) Effect of Low-Temperature Plasma on the Structure of Seeds, Growth and Metabolism of Endogenous Phytohormones in Pea (Pisum sativum L.). Plasma Chemistry and Plasma Processing, 35, 659-676. https://doi.org/10.1007/s11090-015-9627-8

[37] Dröge, W. (2002) Free Radicals in the Physiological Control of Cell Function. Physiological Reviews, 82, 47-95.

[38] Arc, E., Galland, M., Godin, B., Cueffand, G. and Rajjou, L. (2013) Nitric Oxide Implication in the Control of Seed Dormancy and Germination. Frontiers in Plant Science, 4, 1-13. https://doi.org/10.3389/fpls.2013.00346

[39] Dhayal, M., Lee, S.Y. and Park, S.U. (2006) Using Low-Pressure Plasma for Carthamus tinctorium L. Seed Surface Modification. Vacuum, 80, 499-506. https://doi.org/10.1016/j.vacuum.2005.06.008

[40] Zhou, Z.W., Huang, Y.F., Yang, S.Z. and Chen, W. (2011) Introduction of a New Atmospheric Pressure Plasma Device and Application on Tomato Seeds. Agricultural Science, 2, 23-27. https://doi.org/10.4236/as.2011.21004

[41] Wu, A.J., Zhang, H., Li, X.D., Lu, S.Y., Du, C.M. and Yan, J.H. (2014) Spectroscopic Diagnostics of Rotating Gliding Arc Plasma Codriven by a Magnetic Field and Tangential Flow. IEEE Transactions on Plasma Science, 42, 3560-3568. https://doi.org/10.1109/TPS.2014.2358255

[42] Zhang, W.J. and Bjorn, L.O. (2009) The Effect of Ultraviolet Radiation on the Accumulation of Medical Compounds in Plants. Fitoterapia, 80, 207-212. https://doi.org/10.1016/j.fitote.2009.02.006

[43] Grzegorzewski, F., Rohn, S., Kroh, L.W., Geyer, M. and Schluter, O. (2010) Surface Morphology and Chemical Composition of Lamb's Lettuce (Valerianella locusta) after Exposure to a Low-Pressure Oxygen Plasma. Food Chemistry, 122, 1145-1152. 
https://doi.org/10.1016/j.foodchem.2010.03.104

[44] Adetimirin, V.O. (2008) Stand Establishment and Early Field Vigor Variation in a Tropicalised Shrunken-2 Maize Population. Field Crops Research, 108, 143-149. https://doi.org/10.1016/j.fcr.2008.04.007

[45] Matra, K. (2016) Non-Thermal Plasma Germination Enhancement of Radish Seeds. Procedia Computer Science, 86, 132-135. 